\title{
Study on Evaluation of Urban Economic Vitality in Guangxi Province
}

\author{
Weize Wang, Ruqun $\mathrm{He}^{a}$, Xing Gao \\ College of Economic and Management, Guangxi Normal University, Guilin 541006, China \\ a2216113971@qq.com
}

Keywords: Guangxi District; economic vitality; factor analysis; evaluation; countermeasures.

\begin{abstract}
Guangxi is in the west and has four advantages in terms of location, resources, ecology, and policies. The potential for development is huge. However, various reports and data show that the level of economic development in Guangxi is relatively low, and the speed is slow, creating a contrast. In this paper, 14 cities in Guangxi are selected as research objects, and factor analysis method is used to evaluate the urban economic vigor of Guangxi in 2016. According to factor scores, these cities are sorted and divided into three levels. The results show that the economic vitality of the city most of the Beibu Gulf Economic Zone is stronger than other cities, to a certain extent, the establishment of the Beibu Gulf Economic Zone has a significant role in promoting the economic vitality of the city.
\end{abstract}

\section{Foreword}

"Economic vitality and sustainable development organizations" define economic vitality as: a community's economic competitiveness, adaptability, and ability to attract private enterprises and public enterprises; Economically active communities can provide residents with satisfactory employment and other economic activities as well as long-term sustainable quality of life; Being able to discover opportunities and seize opportunities at any time, committing to increasing the welfare of residents; To encourage, recognize community residents and business innovation, hard work, high moral character, and participation in community activities. 2016 CCTV selected the Shenzhen, Beijing, Shanghai and other cities as "China's top ten most economically dynamic cities", Hancheng As the only third-tier cities are also among them. This has led to a series of reflections, which factors affect the economic vitality of the city, how to evaluate the economic vitality of the city, and how to enhance the economic vitality of the city. These issues have received extensive attention.

The first part of this paper elaborates the research results of experts and scholars in economic vitality. The second part is mainly an empirical analysis of 14 cities in Guangxi: First of all, it summarizes the current status of urban economic development in Guangxi, and then selects indicators of economic vitality, and lists each of the 9 factors with 9 indicators.,collect and organize data, factor analysis using SPSS18.0 software to determine the final indicator system, find out the economic vitality score of each city, The 14 cities were divided into three levels: strong economic vitality, medium economic vitality, and weak economic vitality. Finally, they reached conclusions and made recommendations.

\section{An Empirical Analysis of Urban Economy Vitality in Guangxi}

\subsection{The Status Quo of Urban Economic Development in Guangxi}

Although Guangxi is a major channel for the southwest China, it has geographical advantages along the river, along the border, and along the coast, However, because of historical reasons, many development opportunities have been missed, and they have been lagging behind in the country. In recent years, the economic development level of cities in Guangxi has been greatly improved, but there is still a gap with the national average, at present, the whole area is in the initial stage of urbanization. In general, the number of cities in Guangxi is small, the size of the city is small, and the size of the city does not go up, which affects the exertion of urban agglomeration and the expansion of the consumer market. Moreover, the level of the central city is not high, and the economic radiation 
ability is weak. It is difficult to play a leading role in the core cities, which seriously restricts the economic development capacity of the urban areas in Guangxi.

In 2016, the region's economy achieved a good start in the "13th Five-Year Plan", GDP 1824.507 billion yuan, an increase of $7.3 \%$ last year, Among them, the primary industry added value was 279.861 billion yuan, an increase of $3.4 \%$; the secondary industry added value was 821.98 billion yuan, an increase of $7.4 \%$; The added value of the tertiary industry was 722.66 billion yuan, an increase of $8.6 \%$, the contribution rate to economic growth is $7.2 \%, 47.0 \%$ and $45.8 \%$ respectively, the per capita regional GDP was 37,876 yuan, an increase of $7.6 \%$. Slower economic growth stabilized and stable employment situation. The entire region is constantly adjusting its structure and changing modes. The economic structure has undergone marked changes and the development coordination has been further enhanced; Fully promote popular entrepreneurship and innovation, actively promote industrial transformation and upgrading, and increase investment in innovation; The region gradually improved its strategy of opening to the outside world and continued to accelerate the pace of economic and trade cooperation with ASEAN countries. In 2016, the bilateral trade volume with ASEAN reached 183.544 billion-yuan, accounting for nearly $60 \%$ of the total import and export volume of the region; The real growth rate of per capita disposable income of rural residents was faster than that of towns by 2.1 percentage points. The difference in disposable income between urban and rural residents was 2.73 , which was a decrease of 0.06 from the previous year. The income gap between urban and rural areas in the region was further reduced.

\subsection{The Choice of Indicators}

Urban economic vitality is the ability and potential of an area for economic development during a period. It is also reflected in the ability of the economy to grow, the ability to attract capital and attract highly qualified labor. After collecting the literature data studied by experts and scholars, and combining the current situation of Guangxi's economic development, the final decision was made to determine the index system of Guangxi's urban economic vitality measurement from 28 indicators of 10 influencing factors. the primary indicators are shown in Table 1.

Table 1. Preliminary Indicators of Guangxi Economic Activity Measurement

\begin{tabular}{|c|c|c|c|}
\hline No. & Influencing factors & index & unit \\
\hline 1 & \multirow{3}{*}{ Economic benefits } & GDP index & $(\%)$ \\
\hline 2 & & Per capita GDP & (yuan) \\
\hline 3 & & Per capita GDP growth rate & $(\%)$ \\
\hline 4 & \multirow{2}{*}{ Open to the outside world } & Total number of visitors received throughout the year & (Ten thousand people) \\
\hline 5 & & Foreign Trade Import and Export Index & $(\%)$ \\
\hline 6 & Human Resources & Natural population growth rate & $(\%)$ \\
\hline 7 & \multirow{2}{*}{ investment } & Total investment in fixed assets accounts for the proportion of the province & $(\%)$ \\
\hline 8 & & Fixed Assets Investment Index & $(\%)$ \\
\hline 9 & \multirow{3}{*}{ Government regulation } & Per capita fiscal revenue & (yuan) \\
\hline 10 & & Government's fiscal revenue as a percentage of GDP & $(\%)$ \\
\hline 11 & & General public budget fiscal expenditure as a percentage of GDP & $(\%)$ \\
\hline 12 & \multirow{4}{*}{ Innovative Technology } & Annual application for the number of patents & (One) \\
\hline 13 & & Number of technicians engaged in scientific research & (One) \\
\hline 14 & & R\&D expenditure internal expenditure as a percentage of GDP & $(\%)$ \\
\hline 15 & & Funding for science and technology accounts for the proportion of local fiscal expenditure & $(\%)$ \\
\hline 16 & \multirow{5}{*}{ Wages } & Total payroll index for all employees & $(\%)$ \\
\hline 17 & & Average money wage & (yuan) \\
\hline 18 & & State-owned economy average currency wage & (yuan) \\
\hline 19 & & Urban Collective Economy Average Currency Wages & (yuan) \\
\hline 20 & & Other kinds of economic average currency wages & (yuan) \\
\hline 21 & \multirow{3}{*}{ Industrial Enterprises } & Revenue from Main Business of Industrial Enterprises above Designated Size & (Billion) \\
\hline 22 & & The growth rate of main business income of industrial enterprises above designated size & $(\%)$ \\
\hline 23 & & The cost profit margin of industrial enterprises above designated size & $(\%)$ \\
\hline 24 & \multirow{5}{*}{ Social Security } & Urban residents' disposable income & (yuan) \\
\hline 25 & & Per capita net income of rural residents & (yuan) \\
\hline 26 & & Total retail sales of consumer goods & $(\%)$ \\
\hline 27 & & Percentage of population participating in urban basic pension insurance & (yuan) \\
\hline 28 & & unemployment rate & $(\%)$ \\
\hline
\end{tabular}




\subsection{Empirical Process}

\section{Factor analysis}

Based on the index of economic vitality determined by the above-mentioned preliminary selection, factor analysis of economic viability of 14 cities using SPSS 18.0, However, through the analysis of the results, these matrices are non-definite matrices, indicating that the above identified indicators cannot be factor-analyzed. According to the obtained correlation matrix, the index with lower absolute value of correlation and the index with unilateral value greater than 0.10 were excluded, and the remaining GDP index and natural population growth rate were 9 indicators. After testing, the results show that the KMO value is 0.594 ; Bartlett's test value is 85.213 , Sig. $=0.000$, It shows that the $\mathrm{KMO}$ test and the Bartlett sphere test have passed, and the 9 indicators after screening can be used for factor analysis.

Testing by KMO and Bartlett

\begin{tabular}{|cc|c|}
\hline Kaiser-Meyer-Olkin metric for sampling enough. & .594 & 85.213 \\
& square & 36 \\
Bartlett's Sphericity Test Approximate Chi & df & Sig. \\
\hline
\end{tabular}

Next, an analysis of the economic vitality of each city in Guangxi based on the indicator system consisting of 9 indexes including GDP index and natural population growth rate is shown in the table below:

Table 2. Guangxi Economic Vitality Evaluation Index System

\begin{tabular}{c|c|c}
\hline No. & index & unit \\
\hline 1 & GDP index & $\%$ \\
\hline 2 & Per capita GDP growth rate & $\%$ \\
\hline 3 & Natural population growth rate & $\%$ \\
\hline 4 & Fixed Assets Investment Index & $\%$ \\
\hline 5 & Government's fiscal revenue as a percentage of GDP & $\%$ \\
\hline 6 & Funding for science and technology accounts for the proportion of local fiscal expenditure & $\%$ \\
\hline 7 & Total retail sales of consumer goods & $\%$ \\
\hline 8 & Revenue from Main Business of Industrial Enterprises above Designated Size & Billion \\
\hline 9 & Average money wage & yuan \\
\hline
\end{tabular}

The principal component analysis method was used to extract factors with eigenvalues greater than one. The results showed that three of the factors met the criteria, and the characteristic roots were $3.590,2.375$, and 1.067, respectively. And the total variance of the three factors explained more than $78 \%$, explains the clear majority of the selected indicators, fully meet the requirements of the factor analysis, so choose three factors for analysis.

Table 3. Factor variance contribution rate

\begin{tabular}{c|c|c|c|c}
\hline \multicolumn{2}{|c|}{ factor } & F1 & F2 & F3 \\
\hline \multirow{2}{*}{ Initial feature value } & Eigenvalues & 3.59 & 2.375 & 1.067 \\
\cline { 2 - 5 } & Variance contribution rate (\%) & 39.887 & 26.389 & 11.852 \\
\cline { 2 - 5 } & Accumulated variance contribution rate (\%) & 38.887 & 66.275 & 78.128 \\
\hline \multirow{3}{*}{ Main factor variance contribution rate } & Eigenvalues & 3.59 & 2.375 & 1.067 \\
\cline { 2 - 5 } & Variance contribution rate (\%) & 39.887 & 26.389 & 11.852 \\
\cline { 2 - 5 } & Accumulated variance contribution rate (\%) & 39.887 & 66.275 & 78.128 \\
\hline \multirow{3}{*}{ Variance contribution rate after factor rotation } & Eigenvalues & 3.122 & 2.806 & 1.103 \\
\cline { 2 - 5 } & Variance contribution rate (\%) & 34.694 & 31.18 & 12.253 \\
\cline { 2 - 5 } & Accumulated variance contribution rate (\%) & 34.694 & 65.874 & 78.128 \\
\hline
\end{tabular}

To make the extracted common factor interpretation result clearer, the maximum variance method is used for factor rotation. The results show that the eigenvalues of the three factors are still greater than 1 , which are $3.122,2.806$, and 1.103 , respectively. The interpretation of the total variance is 
$78.128 \%$. These three factors can explain most of the selected indicators. The interpretation ratio of the three factors to the total variance is $34.694 \%, 31.180 \%$, and $12.253 \%$, respectively.

As shown above, the rotation component matrix takes only data with an absolute value greater than 0.55. Factor 1 is mainly influenced by the GDP index, fixed assets investment index, per capita GDP growth, and the average currency wage index, GDP index and per capita GDP growth reflect economic production, Fixed assets investment index reflects the trend of economic development and investment level, The average money wage reflects the overall level of wages and spending power. Therefore, factor 1 is named as the basic factor of economic development; Factor 2 is mainly influenced by the government's fiscal revenue as a percentage of GDP, the proportion of science and technology appropriations to local fiscal expenditure, and the main business income of industrial enterprises above designated size. The ratio of government revenue to GDP reflects the government's ability to control the national economy, The allocation of science and technology funds to local fiscal expenditures reflects the government's support for technological innovation and other aspects, The main business income of industrial enterprises above designated size reflects the development of industrial enterprises. Therefore, the factor 2 is named government regulation and enterprise benefit factor; Factor 3 is mainly affected by indicators such as the natural population growth rate and the total retail sales of consumer goods. The natural population growth rate reflects human resources.,the index of total retail sales of consumer goods reflects the level of consumption. Therefore, the factor 3 is named as human resources and consumption level factor.

According to the component score coefficient matrix, weights of factor 1, factor 2, and factor 3 are weighted to obtain the influence of each index on the total factor.

Use the component score coefficient matrix multiplied by the index standardization factor score:

$$
F_{i}=\alpha_{i 1} x_{1}^{\prime}+\alpha_{i 2} x_{2}^{\prime}+\alpha_{i p} x_{p}^{\prime}(p=1,2, \ldots, m)
$$

Where: $F_{i}$ denotes the $i$ th factor score; $x_{1}, x_{2}, \ldots x_{p}$, denotes the indicator normalized value; $\alpha_{i 1}, \alpha_{i 2}, \ldots \alpha_{i p}$ denotes the component score coefficient.

The total factor score is equal to the weighted average of the scores of the individual factors:

$$
F=\sum b_{i} F_{i}\left(\sum b_{i}=1\right)
$$

Where $F$ represents the total factor score, which represents the $i$ th factor score; $b_{i}$ represents the degree of contribution of the $i$ th factor. (Dividing factor contribution $=$ division factor rotation variance ratio / total variance interpretation rate)

\begin{tabular}{|c|c|c|c|c|}
\hline index & F1 & $\mathrm{F} 2$ & F3 & $\mathrm{F}$ \\
\hline GDP index & 0.303 & -0.004 & 0.028 & 0.137 \\
\hline Natural population growth rate & 0.030 & 0.087 & 0.762 & 0.168 \\
\hline Fixed Assets Investment Index & 0.243 & 0.030 & -0.130 & 0.099 \\
\hline Government's fiscal revenue as a percentage of GDP & -0.045 & 0.349 & 0.105 & 0.136 \\
\hline Funding for science and technology accounts for the proportion of local fiscal expenditure & -0.006 & 0.298 & -0.054 & 0.108 \\
\hline Total retail sales of consumer goods & 0.155 & 0.099 & -0.547 & 0.023 \\
\hline Per capita GDP growth rate & 0.309 & -0.036 & 0.021 & 0.126 \\
\hline Revenue from Main Business of Industrial Enterprises above Designated Size & -0.071 & 0.329 & 0.088 & 0.114 \\
\hline Average money wage & -0.248 & 0.187 & -0.070 & -0.046 \\
\hline
\end{tabular}

Table 4. Economic Viability Factor Score Factor

From Table 4, we can see that among the 9 indicators selected, the 8 indicators such as the GDP index and the natural population growth rate have a positive impact on economic activity, Only the average currency wage index has an overall adverse effect on economic activity.

\subsection{Empirical Results}

According to the contribution of the basic factors of economic development, government regulation and corporate efficiency factors, and human resources and consumption level factors to the total factor, Combining the scores of various indicators, the scores of the factors for the cities of Guangxi in 2016 were obtained. Table 5: 
Table 5. Factor scores of cities in Guangxi in 2016

\begin{tabular}{|c|c|c|c|c|c|c|c|c|}
\hline city & F1 score & Precedence & F2 score & Precedence & $\begin{array}{c}\text { F3 } \\
\text { score }\end{array}$ & Precedence & Total factor score & Precedence \\
\hline Nanning & -0.9138 & 12 & 1.72586 & 2 & -0.3558 & 10 & 0.227 & 6 \\
\hline Liuzhou & -0.34203 & 11 & 1.80052 & 1 & 0.42346 & 6 & 0.633 & 3 \\
\hline Guilin & -0.16356 & 10 & 0.3708 & 5 & -1.74496 & 13 & -0.198 & 11 \\
\hline Wuzhou & 0.00989 & 8 & -0.50351 & 9 & 1.32955 & 1 & 0.012 & 8 \\
\hline Beihai & 0.46719 & 7 & 1.44985 & 3 & 0.71862 & 4 & 0.899 & 1 \\
\hline Fangchenggang & 0.9058 & 2 & -0.47215 & 8 & 0.69502 & 5 & 0.323 & 4 \\
\hline Qinzhou & 1.28418 & 1 & 0.4168 & 4 & -0.30321 & 9 & 0.689 & 2 \\
\hline Guigang & 0.78386 & 3 & -0.85514 & 12 & 0.0484 & 8 & 0.014 & 7 \\
\hline Yulin & 0.43078 & 6 & -0.27189 & 6 & 1.00519 & 3 & 0.24 & 5 \\
\hline Baise & 0.68796 & 5 & -0.29821 & 7 & -1.78791 & 14 & -0.094 & 9 \\
\hline Hezhou & -0.13474 & 9 & -0.59668 & 10 & 1.1669 & 2 & -0.114 & 10 \\
\hline Hechi & -1.42989 & 13 & -0.69756 & 11 & -0.77731 & 12 & -1.035 & 13 \\
\hline Laibin & -2.33232 & 14 & -0.9526 & 13 & 0.30459 & 7 & -1.368 & 14 \\
\hline Chongzuo & 0.74668 & 4 & -1.11609 & 14 & -0.72256 & 11 & -0.227 & 12 \\
\hline
\end{tabular}

From the table, you can see the scores of each factor and total factor scores of each city, In combination with total factor scores, GIS software is used to rank the economic vigor of cities in Guangxi. Economic dynamism scored between 0.100 and 1.000 is a region with strong economic vitality, the economic vitality score is between -0.100 and 0.100 in the economically active region, Economic vitality scores between -2.80 and -1.000 are areas of weak economic activity; In order to better describe the results, the Beibu Gulf Economic Zone is also marked with slashes in the map. As shown in Figure 1, cities with strong economic vitality include Beihai, Qinzhou, Liuzhou, Fangchenggang, Yulin and Nanning; The economically viable cities are Guigang, Luzhou, Baise, and Hezhou; The economically weak cities include Guilin, Chongzuo, Hechi and Laibin. It can also be seen from the figure, the distribution of urban economic vitality in Guangxi is relatively concentrated, cities with strong economic vitality are mainly distributed in the Beibu Gulf Economic Zone.

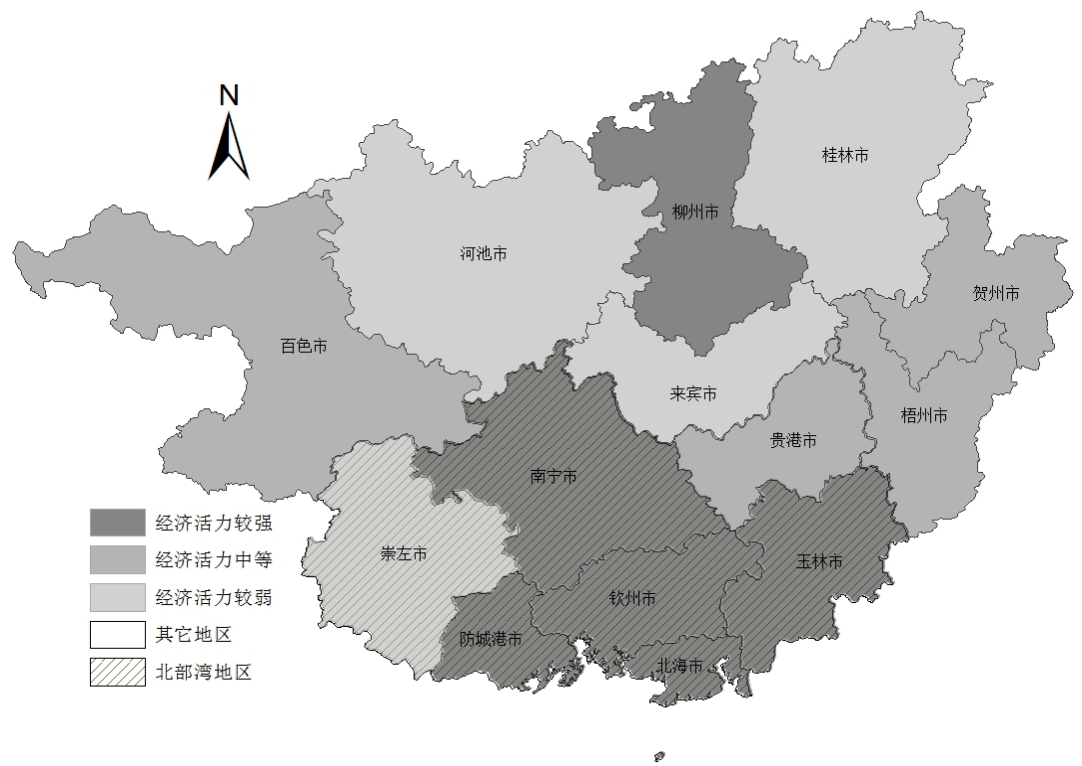

Figure 1. Distribution of urban economic vitality in Guangxi

\section{Conclusion and Recommendation}

\subsection{Conclusion}

According to the empirical results, the 8 indicators such as the GDP index and the natural population growth rate have a positive impact on economic activity. The speed of economic growth 
reflects the economic quality. When other indicators are constant, the higher the GDP index and per capita GDP growth, the stronger the economic viability of the city. Natural population growth rate reflects the natural growth trend and speed of the urban population. Guangxi has the characteristics of sparse population and relatively low labor productivity. The development of the regional economy is inseparable from the labor force in the region; The increase in the population's natural growth rate increases the density of urban population and has a positive impact on the economic vitality of the city. The ratio of government revenue to GDP is one of the manifestations of regional government regulation. There are government macroeconomic controls in China's market economy, this has also promoted the rapid development of China's economy and has also had a positive impact on the economic vitality of the city; Consumption is the driving force of economic development. The index of total retail sales of consumer goods promotes the growth of urban economic vitality; Industrial enterprises are the main carriers of the economy, and their effectiveness is a manifestation of economic vitality. The income from main operations of industrial enterprises above designated size has a positive effect on economic vitality; Science and technology are primary productivity, innovation is economic vitality support, the allocation of science and technology funds to local fiscal revenue reflects the support of regional governments for science and technology. The greater the ratio, the stronger the economic viability of the city; The average money wage index has an overall negative impact on economic activity, the average money wage reflects the basic wage level, indicating that the higher the wage level, the smaller the room for growth and the suppression of the economic vitality of the city. The vitality of economic vitality comes from the foundation of economic development, science and technology, corporate benefits, and social security. It also comes from national policies and government support. Only by closely following the pace of the times, discovering opportunities and grasping opportunities, can we continuously improve the city's economic quality and speed of development, thereby strengthening the city's economic vitality, and the ability to attract capital and attract highly qualified labor.

On the other hand, from the distribution of cities with moderate economic vitality and weak economic vitality, cities closer to Guangdong Province are more economically viable than cities close to Guizhou Province. Over the years, Guangdong Province has far surpassed Guizhou Province both in terms of economy and comprehensive evaluation. Explain that to a certain extent, the economic radiation of neighboring provinces has affected the economic vitality of cities in Guangxi. Due to limited space, this article no longer continues to study.

\subsection{Recommendation}

In summary, several suggestions have been made. In order to enhance the economic vitality of the city, I believe that it can be strengthened from the following aspects: 1, Strengthen investment efforts to make up for the insufficiency of private investment and foreign investment and safeguard the development of the public domain; 2, Strengthen the ability of scientific and technological innovation, upgrade the technological level, and introduce high-level technical personnel, and science and technology are the primary motive force; 3, In order to increase the efficiency of industrial enterprises, the economic benefits of industrial enterprises are generally low, regardless of whether they are in various cities in Guangxi or in the entire western region, and need to be improved. 4, Improving residents' income and social security levels will, to a certain extent, stimulate consumption, expand demand, and reduce savings.

\section{References}

[1]. Bizhao Li. Discussion on the Urbanization Law and Basic Issues of China's Urbanization Development Strategy[J]. Journal of the Humanities, 1988(4):37-44.

[2]. Shenglan Wang, Li Ding, Ye Xiaomei, et al. Study on Fuzzy Comprehensive Evaluation of Urban Vitality_-Taking Major Cities in Hubei as an Example [J]. Journal of Central ChinaNormal University (Natural Sciences), 2013,47(3):440-445. 
[3]. Haijun Lou, Sun Qiubi. Research on the Evaluation of Economic Vigor of Provinces in China Based on Factor Analysis [J]. Journal of Fuzhou University (Philosophy and Social Sciences), 2005,19(3):32-35.

[4]. Faping Sun, Ma Hongbo, Wang Lanying. Research on Improving Qinghai's Economic Vitality [J]. Qinghai Ethnic Research,2007,18(3):87-93.

[5]. Yanbiao Cao. Research on the Talent Activity Based on the Promotion of Regional EconomicVitality[J]. Reform and Strategy, 2012, 28(4):47-49.

[6]. Wei Yi. Construction of Evaluation Index System for Regional Economic Activity in Sichuan Province[J]. Journal of Sichuan Vocational and Technical College, 2015, 25(1):23-25.

[7]. Rongtao Hou. Construction of Economic Vitality Evaluation System and Empirical Analysis of Futian District [J]. Economist, 2015(6):146-148.

[8]. Xiaoli Lu, Guo Wanshan. Comprehensive Evaluation Index System of Urban Economic Activity [J]. Statistics and Decision, 2007(11):77-78.

[9]. Hongdong Zhang, Qin Zhenyan. Analysis of the Structure of Urban Economic Activity[J]. Science and Technology Innovation, 2011(21):155-155.

[10]. Yinghui Yan. The formation and development of the most economically viable cities[J] Journal of Qingdao Administrative College of Qingdao Municipal Party School, 2005(1):61-63.

[11]. Yanjie Jin. Evaluation of Urban Economy in China[J]. Geography Science, 2007, 27(1):9-16.

[12]. Wan Huan, Dafu Jiang. Empirical Analysis of Comprehensive Evaluation of Urbanization Level in Guangxi District [J]. Market Modernization, 2008(34):273-274. [13] Pugalis L. Cultural and economic vitality - the role of place quality [J]. Town \& Country Planning, 2009.

[13]. Konopnicki P M. The Economic Vitality Formula of Success[J]. Techniques Connecting Education \& Careers, 2012, 87:36-39.

[14]. Prall D. Infrastructure jobs important to economic vitality [J]. American City \& County Exclusive Insight, 2014. 